\title{
Characteristics and Treatment Outcome of Culture- positive Tuberculosis Patients among Rural and Urban Residents in Jiangxi, China: a Cross-sectional Study
}

Jiahuan Zhang

Nanchang University

Guimei Chen

Nanchang University

Guangchu Xiong

Jiangxi provincial chest hospital

Dong Luo

Nanchang University

Yiping Peng

Jiangxi provincial chest hospital

\section{Xiaowen Chen}

NANCHANG UNIVERSITY

Lingbing Zeng

NANCHANG UNIVERSITY

Kaisen Chen ( $\nabla$ chenks100@126.com )

Nanchang University https://orcid.org/0000-0003-1498-2538

\section{Research}

Keywords: Tuberculosis, Treatment outcomes, Rural China

Posted Date: June 18th, 2021

DOl: https://doi.org/10.21203/rs.3.rs-621030/v1

License: (c) (1) This work is licensed under a Creative Commons Attribution 4.0 International License. Read Full License 


\section{Abstract}

\section{Background}

Tuberculosis remains a serious public health challenge in China and disproportionately affects urban and rural population. This study aimed to investigate the characteristics and treatment outcome of tuberculosis patients among a population with mixed rural and urban inhabitants.

\section{Methods}

Clinical and socio-demographic information was collected for each culture-confirmed tuberculosis (TB) patients (with $>15 \mathrm{yrs}$ ) from January 1st, 2015 to July 31st, 2017 in a provincial TB designated hospital in Jiangxi, China. We conducted both first- and second-line drug susceptibility testing. A multivariate logistic regression analysis was employed to calculate odds ratios for factors associated with the rural and urban culture-positive tuberculosis patients.

\section{Results}

Overall, 381 culture-confirmed TB patients were enrolled, of which 302 were from rural and 79 from urban region. Rural patients were more likely to have previous treatment history, be unemployed, less educated, and had a slightly higher rate of multidrug-resistant TB. Urban TB patients had a similar rate (40.5\%) of treatment failure with that among rural patients (34.8\%). In the final model, individuals with less education (aOR, 3.32, 95\% $\mathrm{Cl}$ [1.31-8.39]), having sputum smear positive results (2.14 [1.34-3.42]), and with multidrug-resistant TB (4.49 [1.09-18.55]) were associated with treatment failure.

\section{Conclusions}

Despite the distinct social-demographic characteristics, both TB patients from rural and urban population had high unfavorable treatment outcome.

\section{Background}

Tuberculosis (TB) remains a serious public health problem worldwide, with 2.2 million new cases in 2019 [1]. China has the second-largest tuberculosis epidemic worldwide, just behind India [1]. According to the national TB surveillance, the notification rate of TB is substantially higher in rural than in urban communities, and more than $80 \%$ of prevalent TB were from rural regions $[2,3]$. The baseline TB service is accessible in rural and urban areas of China; however, due to the disproportional richness of health resources in urban areas, many TB patients in rural regions still seek health care in the provincial level hospitals in urban centers in China.

It has been reported that increased notifications and transmission of tuberculosis in the urban region have been predicted as a result of the influx of rural population [4]. Several factors influence TB prevalence in China, and transmission is still a significant challenge [2]. A considerable proportion of TB 
cases in China were clinically defined (i.e., bacterial-negative TB cases), and sputum culture-positive pulmonary TB is considered the primary source of tuberculosis transmission $[5,6]$. There was limited data in understanding the difference between culture-positive TB patients among China's rural and urban populations. In many courtiers in Southern-East Asia, African, and Western Pacific regions, where the proportion of TB cases among rural districts also exceeds 50\%; several characteristics of tuberculosis in the rural community have been found, including age, sex, alcohol users [7], HIV [8], education level [9], undernutrition [10], indoor air population [11], low socioeconomic status [12]. Understanding how these different characteristics impact the TB diagnosis and treatment can help local policy-makers achieve more efficient TB management and control among the two population groups.

China's reform and opening up in the recent thirty years have led many rural populations out of poverty, and even many farmers have become urban residents. However, due to the household registration (hukou system) in China [13], rural residents had less chance to share national welfare treatment. This public welfare includes compulsory education, medical insurance, the primary disease medical insurance system, health knowledge, limited knowledge of tuberculosis, and job opportunities. Furthermore, China's rapid urbanization results in millions of urban migrants leaving their rural hometowns to cities to seek jobs; however, they were less likely to benefit from the local medical insurance, which was bundled with their original born place. Meanwhile, both the high background rate of TB infection from their origins and many barriers they faced in their urban destinations lead to a higher risk of tuberculosis than the local urban residents [14].

According to the latest population survey, Jiangxi province, located in Southeast China, is a big agriculture province, with about 45.6 million inhabitants, and $37 \%$ of the population had urban Hukou status while the remaining $63 \%$ population belonged to rural Hukou until 2017. Jiangxi is one of the highest TB burden provinces in China, with a TB prevalence of 463/100,000 among the general population based on the 2010 national TB epidemiology [2]. However, the characteristics of TB and related epidemiological and clinical patterns among diverse household registered people were limited in Jiangxi province. Here, we applied a cross-sectional study to understand the socio-demographic and clinical characteristics of culture-positive TB cases between rural and urban residents and investigate the associated factors with different treatment outcomes. The research findings will be valuable for the differential management of TB patients.

\section{Methods}

\subsection{Study participants and data source}

A cross-sectional survey was conducted from January 01,2015 , to July 31,2017 , at the provincial TBdesignated hospital, Nanchang city, China. A total of 856 clinical likely TB patients were recruited during this period. During the study period, we obtained the clinical information from patients' medical records: gender, age, sputum smear testing results, TB treatment history, presence of cavities on chest radiograph, HIV status; and epidemiological information from the TB management system, including BMI index, 
behaviors of alcohol, smoking, education status, household registration status (i.e., rural and urban patient), as well as occupation and marital status. According to the national TB control guidelines, a culture-confirmed TB patient would be regarded as "successful or cured" if there are two sequential negative smear testing at the end of the treatment, while would be defined as "completed treatment" if there is no sputum test result by the end of treatment.

\subsection{Clinical isolates collection and drug susceptibility testing}

Three sputa samples at different time points (spot, early, and night) from each patient were collected for the acid-fast bacilli (AFB) test using Ziehl Neelsen (ZN) method followed by Löwenstein-Jensen culture. We used biochemical methods such as nitrate reduction, thiophene carboxylic acid hydrazide, $\mathrm{p}$ nitrobenzoic acid to differentiate Mycobacterium tuberculosis complex (MTBC) and nontuberculosis mycobacteria (NTM). All pulmonary TB patients were following "Diagnostic criteria for pulmonary tuberculosis" issued by the Ministry of Health in China, including individuals who were positive sputum smear, positive sputum culture, and (or) individuals who have pulmonary lesions of tuberculosis that have been confirmed by pathological examination [15].

Overall, 381 patients had culture-positive TB. For all culture-positive M. tuberculosis isolates, drug susceptibility testing (DST) was routinely performed using Bactec MGIT960 to measure susceptibility to eight types of anti-tuberculosis drugs according to the MGIT 960 operating manual. These drugs included isoniazid (INH) $(0.2 \mu \mathrm{g} / \mathrm{ml})$, rifampin (RIF) $(40.0 \mu \mathrm{g} / \mathrm{ml})$, streptomycin (SM) $(4.0 \mu \mathrm{g} / \mathrm{ml})$, ethambutol (EMB) $(2.0 \mu \mathrm{g} / \mathrm{ml})$, ofloxacin (OFL) $(1.0 \mu \mathrm{g} / \mathrm{ml})$, kanamycin (KAN) $(30.0 \mu \mathrm{g} / \mathrm{ml})$, amikacin (AMK) $(40.0$ $\mu \mathrm{g} / \mathrm{ml})$, and capreomycin (CMP) $(40.0 \mu \mathrm{g} / \mathrm{ml})$. Quality control was routinely performed using the reference strain H37Rv (ATCC27294). The results were interpreted according to the relevant published literature [8].

\subsection{Statistical Analysis}

The data from medical records and laboratory results were analyzed using the SPSS statistical software. The results were summarized using descriptive statistics, including frequencies and mean. Chi-square $\left(\chi^{2}\right)$ value and odds ratios (ORs) and $95 \%$ confidence intervals $(\mathrm{Cl})$ were calculated to measure the association between patient characteristics and the outcomes of interest at the univariate and multivariate level. All variables for which the association with treatment outcome had a $P$-value $<0.1$ in the univariate analysis were considered for the multivariate logistic regression model. A method of backward stepwise (likelihood ratio) was used in the multivariable logistic regression analysis. Data of logistic regressions are presented as odds ratio (OR) and 95\% confidence interval $(95 \% \mathrm{Cl})$. All statistical analyses were two-sided, and statistical significance was accepted at $P<0.05$.

\section{Results}




\subsection{Socio-demographic characteristics of culture-positive TB patients}

During this period, among the total 381 culture-positive participants, $79.3 \%$ (302 of 381) were patients from rural areas. Both rural and urban patients had a median age of 52-year-old. Table 1 summarized the baseline characteristics of the two populations. Compared to urban TB patients, rural participants were more likely to have smoking behavior but less likely to be in a high education level $(P=0.04)$. A 73\% (221 of 302) of rural TB patients were unemployed, and the rate was only $38 \%$ (30 of 79) among urban patients $(P<0.01)$ (Table 1). Meanwhile, isolates from urban TB patients were a slightly higher likelihood to be MDR-TB compared to that among rural patients. No significant difference was observed in the other clinical and laboratory characteristics (Table 1). 
Table 1

Characteristics of TB patients with rural and urban household registration status in Jiangxi province.

$\begin{array}{lllll}\text { Characteristics } & \text { Rural Patients }(\mathrm{n}= & \begin{array}{l}\text { Urban Patients }(\mathrm{n}= \\ \mathrm{302} \%)\end{array} & \underset{79, \%)}{P} & \text { value }\end{array} \quad$ OR $(95 \% \mathrm{Cl})$

\section{Sex}

Male

$230(76.2)$

$54(68.4)$

1.00

Female

$72(23.8)$

$25(31.6)$

0.16

$1.48(0.86-$

2.54)

Age, yr

Median (IQR)

$52(38-66)$

$52(32-63)$

0.32

15-34

63 (20.9)

24 (30.4)

1.00

$35-54$

99 (32.8)

$22(27.8)$

0.11

$0.58(0.30-$

1.13)

$\geq 55$

$140(46.3)$

$33(41.8)$

0.11

$0.61(0.33-$

1.13)

Marital status

Unmarried

78 (25.8)

$23(29.1)$

1.00

Married

224 (74.2)

$56(70.9)$

0.56

$0.85(0.49-$

1.47)

\section{Drinking alcohol}

regularly

\begin{tabular}{lllll} 
Yes & $216(71.5)$ & $35(44.3)$ & - & 1.00 \\
\hline No & $86(28.5)$ & $44(55.7)$ & 0.001 & $3.16(1.90-$ \\
& & & & $5.26)$
\end{tabular}

\section{Smoking cigarette} regularly

$\begin{array}{lllll}\text { Yes } & 172(57.0) & 48(60.8) & - & 1.00 \\ \text { No } & 130(43.0) & 31(39.2) & 0.54 & 0.85(0.52- \\ & & & & 1.42)\end{array}$

\section{Educational status}

$\begin{array}{lllll}\text { Tertiary } & 22(7.3) & 11(13.9) & 0.04 & \begin{array}{l}2.29(1.04- \\ 5.06)\end{array} \\ \text { Primary/secondary } & 211(69.9) & 46(58.2) & - & 1.00 \\ \text { Less than primary } & 69(22.8) & 22(27.8) & 0.19 & \begin{array}{l}1.46(0.82- \\ 4.33)\end{array}\end{array}$




\begin{tabular}{|c|c|c|c|c|}
\hline Characteristics & $\begin{array}{l}\text { Rural Patients }(n= \\
302, \%)\end{array}$ & $\begin{array}{l}\text { Urban Patients }(n= \\
79, \%)\end{array}$ & $\begin{array}{l}P \\
\text { value }\end{array}$ & OR $(95 \% \mathrm{Cl})$ \\
\hline \multicolumn{5}{|l|}{ Living situation } \\
\hline Living with family & $190(62.9)$ & $53(67.1)$ & - & 1.00 \\
\hline Single or with friends & $112(37.1)$ & $26(32.9)$ & 0.53 & $\begin{array}{l}0.84(0.50- \\
1.43)\end{array}$ \\
\hline \multicolumn{5}{|l|}{ Occupation status } \\
\hline Employee & $81(26.8)$ & $49(62.0)$ & - & 1.00 \\
\hline Unemployed & $221(73.2)$ & $30(38.0)$ & 0.001 & $\begin{array}{l}0.22(0.13- \\
0.38)\end{array}$ \\
\hline \multicolumn{5}{|l|}{ Tuberculosis category } \\
\hline New & $179(59.3)$ & $62(78.5)$ & - & 1.00 \\
\hline Recurrent & $100(33.1)$ & $13(16.5)$ & 0.002 & $\begin{array}{l}0.38(0.20- \\
0.72)\end{array}$ \\
\hline $\begin{array}{l}\text { Previous treatment } \\
\text { failure }\end{array}$ & $23(7.6)$ & $4(5.1)$ & 0.21 & $\begin{array}{l}0.50(0.17- \\
1.51)\end{array}$ \\
\hline \multicolumn{5}{|l|}{ Chest radiograph } \\
\hline No/minimal change & $137(45.4)$ & $40(50.6)$ & - & 1.00 \\
\hline Moderate change & $133(44.0)$ & $30(38.0)$ & 0.34 & $\begin{array}{l}0.77(0.46- \\
1.31)\end{array}$ \\
\hline Extensive change & $32(10.6)$ & $9(11.4)$ & 0.93 & $\begin{array}{l}0.96(0.42- \\
2.18)\end{array}$ \\
\hline \multicolumn{5}{|l|}{ Cavity } \\
\hline Yes & $52(17.2)$ & $15(19.0)$ & - & 1.00 \\
\hline No & $250(82.8)$ & $64(81.0)$ & 0.71 & $\begin{array}{l}1.12(0.60- \\
2.13)\end{array}$ \\
\hline \multicolumn{5}{|l|}{ Sputum smear } \\
\hline Negative & $138(45.7)$ & $39(49.4)$ & - & 1.00 \\
\hline Positive & $164(54.3)$ & $40(50.6)$ & 0.56 & $\begin{array}{l}0.86(0.53- \\
1.42)\end{array}$ \\
\hline \multicolumn{5}{|l|}{ BMI, kg/m2 } \\
\hline$\geq 18.5$ & $257(85.1)$ & $63(79.7)$ & - & 1.00 \\
\hline$<18.5$ & $45(14.9)$ & $16(20.3)$ & 0.25 & $\begin{array}{l}1.45(0.77- \\
2.73)\end{array}$ \\
\hline
\end{tabular}




\begin{tabular}{|c|c|c|c|c|}
\hline Characteristics & $\begin{array}{l}\text { Rural Patients }(n= \\
302, \%)\end{array}$ & $\begin{array}{l}\text { Urban Patients }(n= \\
79, \%)\end{array}$ & $\begin{array}{l}P \\
\text { value }\end{array}$ & OR $(95 \% \mathrm{Cl})$ \\
\hline \multicolumn{5}{|l|}{ HIV-positive } \\
\hline Yes & $21(7.0)$ & $4(5.1)$ & - & 1.00 \\
\hline No & 281 (93.0) & 75 (94.9) & 0.55 & $\begin{array}{l}1.40(0.47- \\
4.21)\end{array}$ \\
\hline \multicolumn{5}{|l|}{ MDR-TB } \\
\hline Yes & $43(14.2)$ & $5(6.3)$ & - & 1.00 \\
\hline No & $259(85.8)$ & 74 (93.7) & 0.06 & $\begin{array}{l}2.46(0.94- \\
6.43)\end{array}$ \\
\hline
\end{tabular}

We did not observe significantly different chest images of the lesion for clinical features, neither the presence of a cavity (Table 1). Rural TB patients had a slightly higher $7.0 \%$ (21 of 302) of HIV-positive than the $5.1 \%$ (4 of 79 ) among urban participants. Of note was that a significantly high proportion of rural individuals had recurrent TB (i.e., based on the medical records) or previous TB treatment history (treatment failure) $(P<0.01)$, and was almost two times higher ( 40.7 vs. $21.6 \%, \mathrm{OR}, 2.5,95 \% \mathrm{Cl}[1.36-$ 4.78]) than that among urban TB patients. No significant difference was observed for other clinical features, including smear testing and BMI.

\subsection{Risk factors associated with treatment outcome among different populations}

Overall, 137 (35\%) of the total 381 culture-positive TB cases had treatment failure, and 203 had favorable outcomes (successful or completed, Table 2). The rest 41 cases were not included due to the loss of follow-up or other reasons (e.g., death) without a valid outcome record. Thus, we included the 340 TB patients in the analysis of associated factors with treatment outcomes. Rural individuals had a comparable treatment success rate with urban patients (39 vs. $44 \%$, Table 2 ). In the univariate model, we found that individuals with less educated $(P=0.02)$ and smear testing positive $(P=0.001)$ were positively associated with unfavorable treatment outcomes. We compared the results with TB cases of various forms of drug resistance. No significant difference was observed in both first-line and second-line drug resistance cases. However, in the multivariate model, after adjusted for the factors in Table 3, TB patients with MDR were a risk factor for treatment failure (Adjusted OR, 4.49, 95\% CI [1.09-18.55]), as well as the lower educational level (3.32[1.31-8.39]) and smear testing positive (2.14 [1.34-3.42]). 
Table 2

Univariate analysis of treatment outcomes among TB patients in Jiangxi province, China

\begin{tabular}{|c|c|c|c|c|c|c|}
\hline \multirow{2}{*}{$\begin{array}{l}\text { Characteristics } \\
\text { Resident status }\end{array}$} & \multicolumn{2}{|c|}{$\begin{array}{l}\text { Successful/completed } \\
\text { treatment } \\
(n=203, \%)\end{array}$} & \multicolumn{2}{|c|}{$\begin{array}{l}\text { Treatment } \\
\text { failure } \\
(n=137, \%)\end{array}$} & \multirow[t]{2}{*}{$\begin{array}{l}P \\
\text { value }\end{array}$} & \multirow[t]{2}{*}{ OR (95\% Cl) } \\
\hline & & & & & & \\
\hline Rural & 163 & $(80.3)$ & 105 & $(76.6)$ & - & 1.00 \\
\hline Urban & 40 & $(19.7)$ & 32 & $(23.4)$ & 0.41 & $\begin{array}{l}1.24(0.73 \\
2.10)\end{array}$ \\
\hline \multicolumn{7}{|l|}{ Sex } \\
\hline Female & 52 & $(25.6)$ & 36 & $(26.3)$ & - & 1.00 \\
\hline Male & 151 & $(74.4)$ & 101 & (73.7) & 0.89 & $\begin{array}{l}0.97(0.59 \\
1.58)\end{array}$ \\
\hline Age, yr & 49 & $(36-42)$ & 52 & $\begin{array}{l}(37- \\
65)\end{array}$ & 0.28 & \\
\hline \multicolumn{7}{|l|}{ Median (IQR) } \\
\hline $15-34$ & 49 & $(24.1)$ & 31 & $(22.6)$ & - & 1.00 \\
\hline $35-54$ & 73 & $(36.0)$ & 44 & $(32.1)$ & 0.87 & $\begin{array}{l}0.95(0.53- \\
1.71)\end{array}$ \\
\hline$\geq 55$ & 81 & (39.9) & 62 & $(45.3)$ & 0.50 & $\begin{array}{l}1.21(0.69- \\
2.11)\end{array}$ \\
\hline \multicolumn{7}{|l|}{ Marital status } \\
\hline Unmarried & 48 & $(23.6)$ & 36 & $(26.3)$ & - & 1.00 \\
\hline Married & 155 & $(76.4)$ & 101 & (73.7) & 0.58 & $\begin{array}{l}0.87(0.53 \\
1.43)\end{array}$ \\
\hline \multicolumn{7}{|l|}{ Educational level } \\
\hline Tertiary & 24 & $(11.8)$ & 9 & $(6.6)$ & - & 1.00 \\
\hline Primary/secondary & 145 & $(71.4)$ & 91 & $(66.4)$ & 0.21 & $\begin{array}{l}1.67(0.74 \\
3.76)\end{array}$ \\
\hline Less than primary & 34 & $(16.7)$ & 37 & $(27.0)$ & 0.02 & $\begin{array}{l}2.90(1.18 \\
7.11)\end{array}$ \\
\hline \multicolumn{7}{|l|}{ Occupation status } \\
\hline Employee & 67 & (33.0) & 51 & $(37.2)$ & - & 1.00 \\
\hline Unemployed & 136 & $(67.0)$ & 86 & $(62.8)$ & 0.42 & $\begin{array}{l}0.83(0.53 \\
1.31)\end{array}$ \\
\hline
\end{tabular}




\begin{tabular}{|c|c|c|c|c|c|c|}
\hline \multirow{2}{*}{$\begin{array}{l}\text { Characteristics } \\
\text { Drinking alcohol } \\
\text { regularly }\end{array}$} & \multicolumn{2}{|c|}{$\begin{array}{l}\text { Successful/completed } \\
\text { treatment } \\
(n=203, \%)\end{array}$} & \multicolumn{2}{|c|}{$\begin{array}{l}\text { Treatment } \\
\text { failure } \\
(n=137, \%)\end{array}$} & \multirow[t]{2}{*}{$\begin{array}{l}P \\
\text { value }\end{array}$} & \multirow[t]{2}{*}{ OR $(95 \% \mathrm{Cl})$} \\
\hline & & & & & & \\
\hline No & 102 & $(50.2)$ & 65 & $(47.4)$ & - & 1.00 \\
\hline Yes & 101 & $(49.8)$ & 72 & $(52.6)$ & 0.61 & $\begin{array}{l}1.12(0.72, \\
1.73)\end{array}$ \\
\hline \multicolumn{7}{|l|}{ BMI } \\
\hline$\geq 18.5$ & 164 & $(80.8)$ & 120 & $(87.6)$ & - & 1.00 \\
\hline$<18.5$ & 39 & $(19.2)$ & 17 & $(12.4)$ & 0.10 & $\begin{array}{l}0.60(0.32, \\
1.10)\end{array}$ \\
\hline \multicolumn{7}{|l|}{$\begin{array}{l}\text { Smoking cigarette } \\
\text { regularly }\end{array}$} \\
\hline No & 92 & $(45.3)$ & 72 & $(52.6)$ & - & 1.00 \\
\hline Yes & 111 & $(54.7)$ & 65 & $(47.4)$ & 0.19 & $\begin{array}{l}0.75(0.48 \\
1.16)\end{array}$ \\
\hline \multicolumn{7}{|l|}{ HIV sero-positive } \\
\hline No & 190 & $(93.6)$ & 131 & $(95.6)$ & - & 1.00 \\
\hline Yes & 13 & $(6.4)$ & 6 & $(4.4)$ & 0.42 & $\begin{array}{l}0.67(0.25 \\
1.81)\end{array}$ \\
\hline \multicolumn{7}{|l|}{ Smear AFB positive } \\
\hline No & 107 & $(52.7)$ & 47 & (34.3) & - & 1.00 \\
\hline Yes & 96 & $(47.3)$ & 90 & $(65.7)$ & 0.001 & $\begin{array}{l}2.13(1.36 \\
3.34)\end{array}$ \\
\hline \multicolumn{7}{|l|}{ Chest radiograph } \\
\hline No/minimal change & 99 & $(48.8)$ & 58 & $(42.3)$ & - & 1.00 \\
\hline Moderate change & 83 & $(40.9)$ & 59 & $(43.1)$ & 0.41 & $\begin{array}{l}1.21(0.74 \\
1.98)\end{array}$ \\
\hline Extensive change & 21 & $(10.3)$ & 20 & $(14.6)$ & 0.16 & $\begin{array}{l}1.63(0.76 \\
3.44)\end{array}$ \\
\hline \multicolumn{7}{|l|}{ Cavity } \\
\hline No & 171 & $(84.2)$ & 106 & $(77.4)$ & - & 1.00 \\
\hline Yes & 32 & (15.8) & 31 & $(22.6)$ & 0.11 & $\begin{array}{l}1.56(0.90 \\
2.71)\end{array}$ \\
\hline
\end{tabular}




\begin{tabular}{|c|c|c|c|c|c|c|}
\hline \multirow{2}{*}{$\begin{array}{l}\text { Characteristics } \\
\text { MDR-TB }\end{array}$} & \multicolumn{2}{|c|}{$\begin{array}{l}\text { Successful/completed } \\
\text { treatment } \\
(n=203, \%)\end{array}$} & \multicolumn{2}{|c|}{$\begin{array}{l}\text { Treatment } \\
\text { failure } \\
(n=137, \%)\end{array}$} & \multirow[t]{2}{*}{$\begin{array}{l}P \\
\text { value }\end{array}$} & \multirow[t]{2}{*}{ OR $(95 \% \mathrm{Cl})$} \\
\hline & & & & & & \\
\hline No & 179 & (88.2) & 113 & (82.5) & - & 1.00 \\
\hline Yes & 24 & $(11.8)$ & 24 & (17.5) & 0.14 & $\begin{array}{l}1.58(0.86 \\
2.92)\end{array}$ \\
\hline \multicolumn{7}{|l|}{ Streptomycin } \\
\hline Susceptible & 169 & (83.3) & 121 & (88.3) & - & 1.00 \\
\hline Resistance & 34 & $(16.7)$ & 16 & (11.7) & 0.19 & $\begin{array}{l}0.66(0.35 \\
1.24)\end{array}$ \\
\hline \multicolumn{7}{|l|}{ Isoniazid } \\
\hline Susceptible & 167 & (82.3) & 110 & (80.3) & - & 1.00 \\
\hline Resistance & 36 & (17.7) & 27 & (19.7) & 0.64 & $\begin{array}{l}1.14(0.65 \\
1.98)\end{array}$ \\
\hline \multicolumn{7}{|l|}{ Rifampicin } \\
\hline Susceptible & 161 & (79.3) & 103 & $(75.2)$ & - & 1.00 \\
\hline Resistance & 42 & $(20.7)$ & 34 & $(24.8)$ & 0.37 & $\begin{array}{l}1.27(0.76 \\
2.12)\end{array}$ \\
\hline \multicolumn{7}{|l|}{ Ethambutol } \\
\hline Susceptible & 192 & $(94.6)$ & 128 & (93.4) & - & 1.00 \\
\hline Resistance & 11 & (5.4) & 9 & (6.6) & 0.65 & $\begin{array}{l}1.23(0.49 \\
3.05)\end{array}$ \\
\hline \multicolumn{7}{|l|}{ Kanamycin } \\
\hline Susceptible & 200 & (98.5) & 135 & (98.5) & - & 1.00 \\
\hline Resistance & 3 & (1.5) & 2 & (1.5) & 0.98 & $\begin{array}{l}0.99(0.16, \\
5.99)\end{array}$ \\
\hline \multicolumn{7}{|l|}{ capreomycin } \\
\hline Susceptible & 199 & $(98.0)$ & 133 & $(97.1)$ & - & 1.00 \\
\hline Resistance & 4 & (2.0) & 4 & (2.9) & 0.57 & $\begin{array}{l}1.50(0.37 \\
6.09)\end{array}$ \\
\hline \multicolumn{7}{|l|}{ Ofloxacin } \\
\hline Susceptible & 186 & (91.6) & 127 & (92.7) & - & 1.00 \\
\hline
\end{tabular}




\begin{tabular}{|c|c|c|c|c|}
\hline Characteristics & $\begin{array}{l}\text { Successful/completed } \\
\text { treatment } \\
(n=203, \%)\end{array}$ & $\begin{array}{l}\text { Treatment } \\
\text { failure } \\
(n=137, \%)\end{array}$ & $\begin{array}{l}P \\
\text { value }\end{array}$ & OR $(95 \% \mathrm{Cl})$ \\
\hline Resistance & (8.4) & (7.3) & 0.71 & $\begin{array}{l}0.86(0.38 \\
1.94)\end{array}$ \\
\hline
\end{tabular}

Table 3

Multivariate regression analysis of the associated factors with the unfavorable treatment outcomes among rural and urban inhabitants in Jiangxi, China

\begin{tabular}{|lll|}
\hline Characteristics & Adjusted OR (95\%Cl) & Pvalue \\
\hline Educational level & & \\
\hline Tertiary & 1.00 & - \\
\hline Primary/secondary & $1.70(0.74,3.91)$ & 0.210 \\
\hline Less than primary & $3.32(1.31,8.39)$ & 0.011 \\
\hline BMI & & \\
\hline$\geq 18.5$ & $1.00($ Ref $)$ & - \\
\hline$<18.5$ & $0.53(0.28,1.00)$ & 0.050 \\
\hline Smear AFB positive & & - \\
\hline No & $1.00($ Ref $)$ & 0.001 \\
\hline Yes & $2.14(1.34,3.42)$ & \\
\hline MDR-TB & & - \\
\hline No & $1.00($ Ref $)$ & 0.038 \\
\hline Yes & $4.49(1.09,18.55)$ & \\
\hline
\end{tabular}

\section{Discussion}

This study aims to gain insights into TB patients' epidemiological and clinical features with different resident statuses (i.e., the Chinese Hukou system). We also evaluated the associated factors with the treatment outcomes of TB patients. The study results showed that most TB cases were from the rural population, accounted for nearly $80 \%$ of the notified culture-confirmed TB cases. Despite distinct socialdemographic characteristics among these two population groups, they had a similar but low proportion of treatment successful/completed outcome. We also identified several factors associated with treatment failure: the lower education level, smear-positive at diagnosis, and MDR-TB. 
One of the main challenges in TB control in China was the high burden of TB diseases in most rural regions, which accounts for $80 \%$ of the prevalent TB cases in China and is 1.6 times higher in prevalence rate compared to the urban areas [3]. Meanwhile, the healthcare resource and facilities are relatively limited in these rural areas, which led to a medical behavior shift that many rural patients preferred to seek health care in nearby urban centers or even cities in different provinces. This also brings another challenge that the migration of TB patients could contribute to extra transmission events during their healthcare-seeking journey [4]. Our finding of the rural population as TB patients' primary source echoed previous studies in other studies in China. For instance, one study [16] reported similar results that rural residents contributed to $76 \%$ of TB cases in Xinjiang province, China; another study [17] showed that $70 \%$ of TB patients lived in rural areas in Guangzhou province, China, and most rural resident patients were immigrant population from all places in the country.

Rural TB patients had a significantly higher proportion of recurrent TB. One of the most likely explanations for this finding was the healthcare-related barriers due to their household registration status. In most cases, the free TB treatment (only first-line drugs) was not available outside individuals' originally registered residence [4], and this could cause a high medical cost and thus led to poor treatment adherence or TB management in many reports $[4,6,13,14]$. In this context, the management of rural TB patients could be a challenge for local CDC in their original residence. The isolated rate of MDR TB was $12.6 \%$ in our study, significantly different from previous local reports $[2,18]$. Of note is that rural TB patients also had a higher proportion of MDR-TB. This could be why inadequate treatment compliance, lack of economic support, and long disease course were more likely to be associated with rural patients $[19,20]$. A previous national MDR-TB survey in China has found that patients treated in the hospital had a poor outcome than CDC [21], and this is more likely the case for these rural MDR-TB patients. The limited resource in diagnosis and drug supplements in rural regions is still a severe issue that needs immediate improvement in China, particularly laboratory ability in the rural areas' basic community level.

There was no statistically significant difference in the treatment outcomes among the rural and urban TB patients; however, both had a low rate of favorable treatment outcomes. Not surprisingly, we found patients diagnosed with MDR-TB and being smear-positive were independently associated with treatment failure. Among MDR-TB, the treatment success rate was less than $50 \%$-similar to previous reports in other cities and the average level country-wide in China [21, 22]. Besides, the study found that the less the education level, the more likely the individual had treatment failure. It's not clear about this association, but it should be reasonable to anticipate that low education level could be connected with the poor social or economic situation, which may impact the treatment adherence and the ability to afford the medical expense, as well as less knowledge towards TB disease [23-25].

Out of the total 856 pulmonary tuberculosis patients, $2.9 \%$ were HIV positive. Similarly, a meta-analysis conducted in China showed that the co-infection rate of M. tuberculosis in patients infected with HIV was $14.4 \%$ [26]. In China, according to the WHO report in 2017, the co-infection of M. tuberculosis with HIV was $11.0 \%$ [1]. This data indicated that HIV spread is at a low level in Jiangxi province. This study also indicated that HIV seropositive rate was slightly higher among rural culture-positive tuberculosis patients

Page $13 / 18$ 
(7.0\% vs. $5.1 \%)$. However, the difference in its prevalence was not significantly between rural and urban TB patients. The possible reason was many rural-to-urban migrants were the significant risk factors for HIV infection [27].

This study has several limitations, such as L-J solid medium alone may underestimate the diagnosis of culture-positive TB in this study. Secondly, confounding factors like TB drug quality, cavity interpretation, and detailed category of tuberculosis could not be controlled due to the limitation in information in these aspects. Thirdly, the culture-positive rate was $44 \%$-similar to the reported in other parts in China $[6,28,29]$; it could be possible that the diagnosis method was less sensitive and could miss some bacterial-positive cases. But this could also indicate that the clinical-defined, bacterial-negative TB cases were being over diagnosed. In the current study, we only selected those culture-confirmed cases as this is the golden standard. Nevertheless, the findings are undoubtedly beneficial for making public health of priority for developing actions at the prevention and control of TB transmission of various household registration residents in the Jiangxi area, China.

\section{Conclusions}

In summary, this cross-sectional study presented a different figure of the TB patients with the two household registration statuses in China and the treatment outcomes in these two populations. The TB management system should pay more attention to how these differences can impact the patients' healthcare-seeking behaviors and treatment outcomes. More importantly, improve the diagnostic sensitivity, and the treatment of MDR-TB is still the main challenge in this study population, particularly in the rural areas.

\section{Abbreviations}

\begin{tabular}{ll} 
TB & tuberculosis \\
\hline MDR-TB & multidrug-resistant tuberculosis \\
\hline RIF & rifampicin \\
\hline INH & isoniazid \\
\hline EMB & ethambutol \\
\hline SM & streptomycin \\
\hline EMB & ethambutol \\
\hline PZA & pyrazinamide
\end{tabular}

\section{Declarations}


Ethics approval and consent to participate: The study was conducted according to the guidelines of the Declaration of Helsinki, and approved by the Ethics Committee) of the First Affiliated Hospital of Nanchang University (protocol code2014036)." Informed consent was obtained from all subjects involved in the study.

Consent for publication: All authors have read and agreed to the published version of the manuscript.

Availability of data and materials: All data generated or analyzed during this study are included in this published article.

Competing interests: The authors declare no conflict of interest. The funders had no role in the design of the study; in the collection, analyses, or interpretation of data; in the writing of the manuscript, or in the decision to publish the results.

Funding: This research was funded by the National Natural Science Foundation of China (NSFC), grant number 82060611.

Authors' contributions: Conceptualization, J.Z., G.C. and K.C.; methodology, J.Z., G.C. and K.C.; software, J.Z., G.C. and L.Z.; formal analysis, J.Z., G.C. and L.Z.; investigation, J.Z., G.C., G.X., D.L., Y.P. and X.C.; data curation, J.Z., G.C., G.X., D.L., Y.P. and X.C.; writing-original draft preparation, J.Z., G.C., and K.C.; funding acquisition, K.C.

Acknowledgements: We thank staff in the department of clinical laboratory of the First Affiliated Hospital of Nanchang University for providing supports for clinical isolates collection and clinical data abstracting in this study.

\section{References}

1. Organization, W.H. Global tuberculosis report 2019. Availabe online: https://apps.who.int/iris/handle/10665/329368 (accessed on March 29).

2. Chen, K.S.; Liu, T.; Lin, R.R.; Peng, Y.P.; Xiong, G.C. Tuberculosis transmission and risk factors in a Chinese antimony mining community. Int J Tuberc Lung Dis 2016, 20, 57-62, doi:10.5588/ijtld.15.0215.

3. Wang, L.; Liu, J.; Chin, D.P. Progress in tuberculosis control and the evolving public-health system in China. Lancet 2007, 369, 691-696, doi:10.1016/S0140-6736(07)60316-X.

4. Yang, C.; Lu, L.; Warren, J.L.; Wu, J.; Jiang, Q.; Zuo, T.; Gan, M.; Liu, M.; Liu, Q.; DeRiemer, K., et al. Internal migration and transmission dynamics of tuberculosis in Shanghai, China: an epidemiological, spatial, genomic analysis. Lancet Infect Dis 2018, 18, 788-795, doi:10.1016/S1473-3099(18)30218-4.

5. Lu, P.; Ding, X.; Liu, Q.; Lu, W.; Martinez, L.; Sun, J.; Lu, F.; Zhong, C.; Jiang, H.; Miao, C., et al. Mediating Effect of Repeated Tuberculosis Exposure on the Risk of Transmission to Household Contacts 
of Multidrug-Resistant Tuberculosis Patients. Am J Trop Med Hyg 2018, 98, 364-371, doi:10.4269/ajtmh.17-0325.

6. Yang, C.; Shen, X.; Peng, Y.; Lan, R.; Zhao, Y.; Long, B.; Luo, T.; Sun, G.; Li, X.; Qiao, K., et al. Transmission of Mycobacterium tuberculosis in China: a population-based molecular epidemiologic study. Clin Infect Dis 2015, 61, 219-227, doi:10.1093/cid/civ255.

7. $\quad$ Chadha, V.K.; Kumar, P.; Anjinappa, S.; Singh, S.; Narasimhaiah, S.; Joshi, M.V.; Gupta, J.; Lakshminarayana; Ramchandra, J.; Velu, M., et al. Prevalence of Pulmonary Tuberculosis among Adults in a Rural Sub-District of South India. Plos One 2012, 7, doi:ARTN e4262510.1371/journal.pone.0042625.

8. Chamie, G.; Kato-Maeda, M.; Emperador, D.M.; Wandera, B.; Mugagga, O.; Crandall, J.; Janes, M.; Marquez, C.; Kamya, M.R.; Charlebois, E.D., et al. Spatial overlap links seemingly unconnected genotypematched TB cases in rural Uganda. Plos One 2018, 13, doi:ARTN e019266610.1371/journal.pone.0192666.

9. $\quad$ Chen, W.; Shu, W.; Wang, M.; Hou, Y.; Xia, Y.; Xu, W.; Bai, L.; Nie, S.; Cheng, S.; Xu, Y. Pulmonary tuberculosis incidence and risk factors in rural areas of China: a cohort study. Plos One 2013, 8, e58171, doi:10.1371/journal.pone.0058171.

10. Musuenge, B.B.; Poda, G.G.; Chen, P.C. Nutritional Status of Patients with Tuberculosis and Associated Factors in the Health Centre Region of Burkina Faso. Nutrients 2020, 12, doi:10.3390/nu12092540.

11. Dhanaraj, B.; Papanna, M.K.; Adinarayanan, S.; Vedachalam, C.; Sundaram, V.; Shanmugam, S.; Sekar, G.; Menon, P.A.; Wares, F.; Swaminathan, S. Prevalence and risk factors for adult pulmonary tuberculosis in a metropolitan city of South India. Plos One 2015, 10, e0124260, doi:10.1371/journal.pone.0124260.

12. Harling, G.; Lima Neto, A.S.; Sousa, G.S.; Machado, M.M.T.; Castro, M.C. Determinants of tuberculosis transmission and treatment abandonment in Fortaleza, Brazil. BMC Public Health 2017, 17, 508, doi:10.1186/s12889-017-4435-0.

13. Jia, Z.W.; Jia, X.W.; Liu, Y.X.; Dye, C.; Chen, F.; Chen, C.S.; Zhang, W.Y.; Li, X.W.; Cao, W.C.; Liu, H.L. Spatial analysis of tuberculosis cases in migrants and permanent residents, Beijing, 2000-2006. Emerg Infect Dis 2008, 14, 1413-1419, doi:10.3201/eid1409.071543.

14. Shen, X.; Xia, Z.; Li, X.Q.; Wu, J.; Wang, L.L.; Li, J.; Jiang, Y.; Guo, J.T.; Chen, J.; Hong, J.J., et al. Tuberculosis in an Urban Area in China: Differences between Urban Migrants and Local Residents. Plos One 2012, 7, doi:ARTN e5113310.1371/journal.pone.0051133.

15. China, M.o.H.o.t.P.s.R.o. Diagnostic criteria for pulmonary tuberculosis. 2008. 
16. He, X.Y.; Cao, M.Q.; Mahapatra, T.; Duo, X.P.; Mahapatra, S.; Li, Q.F.; Feng, L.; Tangs, S.Y.; Zhao, Z.; Liu, J.B., et al. Burden of tuberculosis in Xinjiang between 2011 and 2015: A surveillance data-based study. Plos One 2017, 12, doi:ARTN e018759210.1371/journal.pone.0187592.

17. $L i, X . ; L i, T . ;$ Tan, S. Males, ages $>/=45$ years, businessperson, floating population, and rural residents may be considered high-risk groups for tuberculosis infection in Guangzhou, China: a review of 136,394 tb confirmed cases. Rev Inst Med Trop Sao Paulo 2013, 55, 366-368, doi:10.1590/S003646652013000500013.

18. Yuan, X.; Zhang, T.; Kawakami, K.; Zhu, J.; Zheng, W.; Li, H.; Deng, G.; Tu, S.; Liu, W. Genotyping and clinical characteristics of multidrug and extensively drug-resistant tuberculosis in a tertiary care tuberculosis hospital in China. BMC Infect Dis 2013, 13, 315, doi:10.1186/1471-2334-13-315.

19. Mulisa, G.; Workneh, T.; Hordofa, N.; Suaudi, M.; Abebe, G.; Jarso, G. Multidrug-resistant Mycobacterium tuberculosis and associated risk factors in Oromia Region of Ethiopia. Int J Infect Dis 2015, 39, 57-61, doi:10.1016/j.jij.2015.08.013.

20. Hutchison, C.; Khan, M.S.; Yoong, J.; Lin, X.; Coker, R.J. Financial barriers and coping strategies: a qualitative study of accessing multidrug-resistant tuberculosis and tuberculosis care in Yunnan, China. BMC Public Health 2017, 17, 221, doi:10.1186/s12889-017-4089-y.

21. Zhao, Y.; Xu, S.; Wang, L.; Chin, D.P.; Wang, S.; Jiang, G.; Xia, H.; Zhou, Y.; Li, Q.; Ou, X., et al. National survey of drug-resistant tuberculosis in China. N Engl J Med 2012, 366, 2161-2170, doi:10.1056/NEJMoa1108789.

22. Xue He, G.; van den Hof, S.; van der Werf, M.J.; Guo, H.; Hu, Y.L.; Fan, J.H.; Zhang, W.M.; Tostado, C.P.; Borgdorff, M.W. Inappropriate tuberculosis treatment regimens in Chinese tuberculosis hospitals. Clin Infect Dis 2011, 52, e153-156, doi:10.1093/cid/cir075.

23. Yen, Y.F.; Yen, M.Y.; Shih, H.C.; Hu, B.S.; Ho, B.L.; Li, L.H.; Hsiao, J.C.; Deng, C.Y. Prognostic factors associated with mortality before and during anti-tuberculosis treatment. Int J Tuberc Lung D 2013, 17, 1310-1316, doi:10.5588/ijtid.12.0888.

24. Agho, K.E.; Hall, J.; Ewald, B. Determinants of the knowledge of and attitude towards tuberculosis in Nigeria. J Health Popul Nutr 2014, 32, 520-538.

25. Chen, W.; Shu, W.; Wang, M.; Hou, Y.C.; Xia, Y.Y.; Xu, W.G.; Bai, L.Q.; Nie, S.F.; Cheng, S.M.; Xu, Y.H. Pulmonary Tuberculosis Incidence and Risk Factors in Rural Areas of China: A Cohort Study. Plos One 2013, 8, doi:ARTN e5817110.1371/journal.pone.0058171.

26. Liu, J.; Lu, B.; Yan, Y. [Meta analysis on the co-infection between Mycobacterium tuberculosis and HIV/AIDS in China]. Zhonghua Liu Xing Bing Xue Za Zhi 2013, 34, 85-90. 
27. Zhang, L.; Chow, E.P.F.; Jahn, H.J.; Kraemer, A.; Wilson, D.P. High HIV Prevalence and Risk of Infection Among Rural-to-Urban Migrants in Various Migration Stages in China: A Systematic Review and Meta-Analysis. Sex Transm Dis 2013, 40, 136-147, doi:10.1097/OLQ.0b013e318281134f.

28. Qi, W.; Harries, A.D.; Hinderaker, S.G. Performance of culture and drug susceptibility testing in pulmonary tuberculosis patients in northern China. Int J Tuberc Lung Dis 2011, 15, 137-139.

29. Chan-Yeung, M.; Kam, K.M.; Leung, C.C.; Wang, J.; Yew, W.W.; Lam, C.W.; Tam, C.M. Populationbased prospective molecular and conventional epidemiological study of tuberculosis in Hong Kong. Respirology 2006, 11, 442-448, doi:10.1111/j.1440-1843.2006.00871.x. 